\title{
EL CONTRATO DE DEFENSA JURÍDICA EN EL ÁMBITO DE LA ADMINISTRACIÓN DE LA CIUDAD AUTÓNOMA DE MELILLA
}

THE LEGAL DEFENSE CONTRACT IN THE FIELD OF THE ADMINISTRATION OF THE AUTONOMOUS CITY OF MELILLA

\section{Antonio Jesús García Alemany}

Técnico de Administración General

Profesor Tutor de Derecho Administrativo del Centro UNED Melilla

A mi padre, Emilio García Soto, ejemplo inalcanzable de trabajo, constancia y sacrificio por sus hijos. Gracias por todo.

Sumario: I. Introducción. II. Posibilidad de proceder a la contratación de un letrado externo por parte de la Ciudad Autónoma de Melilla. III. Naturaleza jurídica de la contratación de un letrado externo por parte de la Ciudad Autónoma de Melilla. IV. Elementos relevantes del procedimiento de contratación de un letrado externo por parte de la Ciudad Autónoma de Melilla. V. Conclusiones

Resumen: El artículo realiza un estudio sobre la configuración del contrato de servicios jurídicos en el ámbito de la Ciudad Autónoma de Melilla, cuestión que ha presentado dudas e interrogantes derivadas de la postura institucional y de sentencias de diferentes órganos jurisdiccionales que han tratado la materia. El autor pretende aclarar la naturaleza jurídica adecuada de estas relaciones entre la Administración y los letrados externos, constatando la necesidad de someterse a un procedimiento de contratación legalmente establecido y analizando los aspectos más relevantes de esa relación contractual controvertida. 
Palabras clave: Servicio Jurídico, Abogados Externos, Ciudad de Melilla, Contratación Administrativa.

Abstract: The article carries out a study on the configuration of the legal services contract in the Autonomous City of Melilla, an issue that has presented doubts and questions derived from the institutional position and judgments of different jurisdictional bodies that have dealt with the matter. The author seeks to clarify the appropriate legal nature of these relations between the Administration and external counsel, ascertaining the need to submit to a legally established contracting procedure and analysing the most relevant aspects of this controversial contractual relationship.

Keywords: Legal Service, External Lawyers, City of Melilla, Administrative Contracting

Recepción original: 23-7-2020

Aceptación original: 12-12-2020

\section{INTRODUCCIÓN}

En la Ciudad Autónoma de Melilla un asunto de especial relevancia pública en los últimos años ha sido el denominado "Caso Abogados", por el cual se trató en la jurisdicción penal la posible existencia de responsabilidades delictivas de diferentes cargos públicos respecto a la contratación de letrados externos sin seguir, presuntamente, los procedimientos de contratación legalmente establecidos.

La conflictividad derivaba fundamentalmente de la práctica existente, antes incluso de la aprobación de su Estatuto de Autonomía, de contratación de abogados privados por parte de la Administración melillense a través de una designación directa sin someterse a las formalidades propias de la normativa contractual administrativa.

Abundando en el examen de la cuestión, y sin ninguna intención de entrar en polémica, sino simplemente añadir algunas consideraciones que puedan servir de reflexión y al ejercicio de responsabilidad en la actuación de los poderes públicos, examinaremos, en primer lugar, la posibilidad de asumir por un letrado externo la defensa en juicio de los intereses de la Ciudad así como naturaleza jurídica de la precitada contratación ante las dudas planteadas derivadas, incluso, de pronunciamientos del propio Tribunal Supremo. 
Después de una breve reseña sobre el órgano competente y el procedimiento legal de contratación, intentaremos concluir en unas reflexiones finales sobre los distintos elementos jurídicos que confluyen en la designación de abogados, que en Melilla quizás no se ha abordado con el debido rigor, dejando esta materia sujeta a cierta inseguridad jurídica.

\section{POSIBILIDAD DE PROCEDER A LA CONTRATACIÓN DE UN LETRADO EXTERNO POR PARTE DE LA CIUDAD AUTÓNOMA DE MELILLA}

Melilla como parte integrante de la Nación española y dentro de su indisoluble unidad, accedió a un régimen de autogobierno particular con la la aprobación de la Ley Orgánica 2/1995, de 13 de marzo que aprueba su Estatuto de Autonomía (en adelante EA) ${ }^{1}$, contado con autonomía para la gestión de sus intereses y plena capacidad para el cumplimiento de sus fines ${ }^{2}$ por lo que sus decisiones pueden someterse a los órganos jurisdiccionales debiendo contar para ello con la adecuada defensa en juicio de sus intereses ${ }^{3}$.

Centrando la cuestión planteada en la posibilidad que tiene la Ciudad de encomendar a un letrado que no forme parte de la plantilla de su Administración, esa defensa y representación en juicio, debemos, en virtud del artículo 30 del EA, remitirnos a la "legislación del Estado sobre Régimen Local", como normativa reguladora de su régimen jurídico sin perjuicio de las especialidades derivadas de la organización propia: "La ciudad de Melilla se rige en materia de procedimiento administrativo, contratos, concesiones expropiaciones, responsabilidad patrimonial, régimen de bienes y demás aspectos del régimen jurídico de su Administración, por lo establecido con carácter general por la legislación del Estado sobre Régimen Local, sin perjuicio de las especialidades derivadas de la organización propia de la Ciudad establecidas por el presente Estatuto".

Si bien la Constitución Española admite en su Disposición Transitoria Quinta la posibilidad de que la Ciudad de Melilla se constituya en Comunidad Autónoma si así lo decide el respectivo Ayuntamiento, por mayoría absoluta de sus miembros y lo autorizan las

1 BOE núm. 62, de 14 de marzo de 1995

Art. 1 de la Ley Orgánica 2/1995 de 13 de marzo

3 Art. 32.1 EA: "Las normas reglamentarias y los actos y acuerdos dictados por la ciudad de Melilla serán impugnables en todo caso ante los órganos competentes de la jurisdicción contencioso-administrativa". 
Cortes Generales mediante Ley Orgánica; la vía utilizada para aprobar el Estatuto de Autonomía fue la opción otorgada por el constituyente en el artículo 144 b) ${ }^{4}$ que permite a las Cortes Generales acordar un Estatuto de Autonomía para territorios no integrados en la organización provincial sin necesidad de contar con la voluntad territorial. La utilización de esta segunda alternativa ha supuesto que la indefinición de la Ciudad no fuera resuelta plenamente, a mi juicio, con la aprobación del Estatuto de Autonomía de Melilla pues si bien el debate sobre la naturaleza jurídica de la Ciudad se ha mantenido fundamentalmente en el ámbito doctrinal, es cierto que en el terreno de aplicación práctica tanto el Tribunal Constitucional $^{5}$ como el Tribunal Supremo ${ }^{6}$ han coincidido en entender que las Ciudades con Estatuto no pueden ser consideradas Comunidades Autónomas sino entidades locales con autonomías reforzadas respecto al régimen general del resto de municipios derivado de sus propios Estatutos de Autonomía ${ }^{7}$.

Sentado lo anterior, debemos, por tanto, conocer la articulación del ejercicio de la defensa en juicio de una entidad local de régimen común, cuestión que no aparece expresamente regulada en la Ley 7/1985, de 2 de abril, reguladora de las Bases de Régimen Local (LBRL) con carácter general y que tampoco, el artículo 54.4 del Real Decreto Legislativo 781/1986, de 18 de abril, que aprueba el Texto Refundido de las Disposiciones Legales Vigentes en Materia de Régimen Local (TRRL), es excesivamente elocuente al respecto, al remitirse a lo que al efecto disponga la Ley Orgánica 6/1985, de 1 de julio, del Poder Judicial (LOPJ): "En cuanto a la representación y defensa en juicio de las Entidades locales, se estará a lo dispuesto por la Ley Orgánica del Poder Judicial".

En este sentido, el artículo 551.3 de la LOPJ, en la redacción dada al mismo por la Ley Orgánica 19/2003, de 23 de diciembre, dispone que "La representación y defensa de las comunidades autónomas y las de los entes locales corresponderán a los letrados que sirvan en los servicios jurídicos de dichas administraciones públicas, salvo que designen abogado colegiado que les represente y defienda. Los aboga-

4 Preámbulo del E.A de Melilla: "El presente Estatuto de Autonomía, establecido de acuerdo con lo previsto en el artículo 144 b) de la Constitución Española, es la expresión jurídica de la identidad de la ciudad de Melilla y define sus instituciones, competencias y recursos, dentro de la más amplia solidaridad entre todos los pueblos de España."

5 Autos 201 y 202 de 2000 y Sentencia 240/2006

6 Sentencia de 23 de diciembre de 2004 y Auto de 31 de enero de 2008

7 GARCÍA ALEMANY, A.J "Régimen Jurídico de la Policía Local de Melilla" Revista Aldaba, no 432018 
dos del Estado podrán representar y defender a las comunidades autónomas y a los entes locales en los términos contenidos en la Ley 52/1997, de 27 de noviembre, de asistencia jurídica al Estado e instituciones públicas y su normativa de desarrollo."

Este criterio se manifiesta en la normativa local en el artículo 221.2 del Real Decreto 2568/1986, de 28 de noviembre, por el que se aprueba el Reglamento de organización, funcionamiento y régimen jurídico de las corporaciones locales (ROF), al señalar que "De acuerdo con lo dispuesto en el artículo 54.4 del Real decreto legislativo 781/1986, de 18 de abril, y en el artículo 447.2 de la Ley orgánica 6/1985, de 1 de julio, del Poder Judicial, la representación y defensa en juicio de los entes locales corresponderán a los letrados que sirvan en los servicios jurídicos de los mismos, salvo que designen abogado colegiado que les represente y defienda".

Es de resaltar que las normas precitadas al tratase de cuestiones relativas a procedimiento, responsabilidad y régimen jurídico, tienen por aplicación del precitado art. 30 del EA el carácter de indisponibles por lo que la Ciudad en su capacidad reglamentaria de organización y funcionamiento de sus instituciones de autogobierno ${ }^{8}$ no puede modificar dichos preceptos sino exclusivamente adaptarlos a las peculiaridades propias de su organización, máxime cuando estamos ante una cuestión procesal cuya competencia legislativa corresponde en exclusiva al Estado9.

Por tanto, la representación y defensa en juicio de la Ciudad Autónoma de Melilla no puede considerarse unívoca, sino que la misma admite diversas modalidades:

\section{1) Representación y defensa por letrados integrados en el Servicio Jurídico propio de la Ciudad.}

Consiste en la atribución a un órgano administrativo específico de la Ciudad, el Servicio jurídico, las funciones de defensa y representación, en su caso, de sus intereses ante los órganos jurisdiccionales. Este Servicio de conformidad con el art $65^{10}$ del Reglamento

8 Arts 6 y 20 de la Ley Orgánica 2/1995 de 13 de marzo que aprueba el Estatuto de Autonomía de Melilla

9 Art. 149.6 CE: El Estado tiene competencia exclusiva sobre las siguientes materias:

.... 6. Legislación mercantil, penal y penitenciaria; legislación procesal, sin perjuicio de las necesarias especialidades que en este orden se deriven de las particularidades del derecho sustantivo de las Comunidades Autónomas.

10 Art. 65 del RGA"1. Se podrán crear órganos administrativos que no se encuentren integrados en la organización jerarquizada de la Administración de la

(C) UNED. Revista de Derecho UNED, núm. 27, 2021 
de Gobierno y Administración de la Ciudad de Melilla (en adelante RGA) ${ }^{11}$ no se integra en la organización jerarquizada de su Administración dependiendo directamente del Presidente, pretendiéndose garantizar el principio de independencia consagrado en el Código Deontológico de la Abogacía ${ }^{12}$ y sin que el principio de jerarquía administrativa pueda suponer una intromisión ilegítima en las estrategias procesales concretas a seguir por los Letrados propios.

El art. 96.1 del RGA complementa, además, la normativa estatal estableciendo que "La representación y defensa en juicio de la Administración de la Ciudad y sus organismos públicos corresponderá a los letrados que integran los Servicios Jurídicos de la Ciudad, sin perjuicio de lo establecido en el art. 551.3 de la Ley Orgánica del Poder Judicial". El apartado segundo del citado art. 96 del RGA añade que "Reglamentariamente se determinará por el Consejo de Gobierno la regulación de los Servicios Jurídicos de la Ciudad", por lo que la normativa reglamentaria de la Ciudad, además de imponer su existencia de manera preceptiva, dispone la necesidad de contar con un reglamento específico del Servicio, si bien esta capacidad para abordar aspectos organizativos y de funcionamiento interno no se ha ejercido al día de la fecha, lo que supone cierto vacío en cuanto a su regulación que debería ser cubierto con el fin de otorgar mayor seguridad a las actuaciones llevadas a cabo en este ámbito.

Actualmente el Servicio Jurídico de la Ciudad lo conforman empleados públicos, con titulación de licenciados en Derecho, pertenecientes al Subgrupo A1, sin formar parte sus respectivas plazas de un Cuerpo específico de letrados ${ }^{13}$ actuando en un doble ámbito, el del marco de la Administración pública melillense a la que pertenecen y el judicial en el que interactúan en el ejercicio de sus funciones; sometiéndose tanto a los principios establecidos por el Texto

Ciudad Autónoma de Melilla, que dependerán directamente del Presidente de la Ciudad Autónoma de Melilla, sin perjuicio de que sus funciones las realicen para toda la Administración de la Ciudad.

2. La composición y las funciones de estos órganos, se determinarán reglamentariamente por el Consejo de Gobierno. Son órganos de este tipo y se encuentran bajo la dependencia directa del Presidente, el Gabinete de Presidencia, el Gabinete de Comunicación, el Gabinete de Protocolo y los Servicios Jurídicos, entre otros similares que pudieran crearse.

3. No obstante, estos órganos emitirán los informes que les sean requeridos por los Consejeros, previa autorización del Presidente de la Ciudad Autónoma de Melilla".

11 BOME extaordinario n ${ }^{\circ} 2$ de 30 de Enero de 2017

12 Aprobado por el Pleno del Consejo General de la Abogacía Española el 6 de marzo de 2019

13 La Relación de Puestos de Trabajo de la Ciudad los denomina puestos de Asesor/a Jurídico/a (BOME n 5598 de 9 de Noviembre de 2018). 
Refundido del Estatuto Básico del Empleado Público ${ }^{14}$ y la función pública local ${ }^{15}$ como a los recogidos en el Estatuto General de la Abogacía ${ }^{16}$.

Como particularidad destacable, estos servidores públicos propios se encuentran exentos de la obligatoriedad de colegiación de conformidad con el art. 544.2 de la LOPJ: "La colegiación de los Abogados, Procuradores y Graduados Sociales será obligatoria para actuar ante los Juzgados y Tribunales en los términos previstos en esta Ley y por la legislación general sobre colegios profesionales, salvo que actúen al servicio de las Administraciones públicas o entidades públicas por razón de dependencia funcionarial o laboral".

\section{2) Representación y defensa por la Abogacía del Estado pre- via suscripción del correspondiente convenio de colabo- ración entre la Administración General del Estado y la Ciudad.}

Además del 551.3 de la LOPJ, el artículo 1.3 de la Ley 52/1997 de 27 de noviembre, de Asistencia Jurídica al Estado e Instituciones Públicas (conforme a la modificación introducida por el artículo 50 de la Ley 14/2000, de 29 de diciembre, de Medidas Fiscales, Administrativas y del Orden Social) ${ }^{17}$ legitima que los Abogados del Estado puedan representar, defender y asesorar a la Ciudad Autónoma si bien exige, para ello, la suscripción del correspondiente convenio de colaboración entre la Administración General del Estado y la propia Ciudad.

En la misma línea se pronuncian los artículos 1.3 f) y 16.1 del Real Decreto 997/2003, de 25 de julio, por el que se aprueba el Reglamento del Servicio Jurídico del Estado al determinar que "El Servicio Jurídico del Estado podrá prestar asistencia jurídica a las corporaciones locales mediante la celebración del oportuno convenio de colaboración".

14 Real Decreto Legislativo 5/2015, de 30 de octubre de aplicación a la Ciudad por su art. $2.1 \mathrm{~b}$ ) y la Disposición Adicional Tercera.

15 Art. 31 del EA: "El régimen jurídico del personal de la ciudad de Melilla será, por lo que se refiere al personal propio, el establecido en la legislación estatal sobre función pública local."

16 Real Decreto 658/2001, de 22 de junio desarrollado en el Código Deontológico de la Abogacía Española aprobado por Acuerdo del Pleno del Consejo General de la Abogacía de 27 de Septiembre de 2002.

17 Art. 1.3 de la Ley 52/1997: "Asimismo, los Abogados del Estado podrán representar, defender y asesorar a las Corporaciones locales en los términos que se establezcan reglamentariamente y a través de los oportunos convenios de colaboración celebrados entre la Administración General del Estado y las respectivas Corporaciones o las Federaciones de las mismas."

(C) UNED. Revista de Derecho UNED, núm. 27, 2021 
Por los preceptos normativos precitados, la opción de que la Abogacía del Estado pueda asistir, defender y representar jurídicamente a la Administración melillense ante los Juzgados y Tribunales se encuentra legalmente sostenida, imponiéndose la obligatoriedad de celebrar el correspondiente convenio de colaboración, con la debida contraprestación económica y siempre que no exista un supuesto de conflicto de intereses, aprobándose por el Consejo de Gobierno en sesión ordinaria de 28 de Octubre de 2011 el Convenio de Asistencia Jurídica entre la Administración General del Estado (Ministerio de Justicia, Abogacía General del Estado-Dirección del Servicio Jurídico del Estado) y la Ciudad Autónoma de Melilla ${ }^{18}$, posteriormente prorrogado, encontrándose actualmente vigente el Convenio de 29 de febrero de 2019 (BOE número 133 de 4 de Junio de 2019).

En virtud de la Cláusula Primera del Convenio la asistencia jurídica prestada por la Abogacía del Estado comprende tanto el asesoramiento jurídico como la representación y defensa ante cualquier jurisdicción y orden jurisdiccional exceptuándose de esta regla los asuntos contenciosos que se sustancien ante los Juzgados de lo Social y de lo Contencioso-Administrativo con sede en Melilla, salvo que ofrezcan un notable y singular relevancia para la Ciudad, y sin perjuicio de la llevanza de recursos devolutivos contra las resoluciones de aquellos ante Tribunales de cualquier orden cuya sede no se encuentre en su territorio.

\section{3) Representación y defensa a cargo de un abogado colegiado.}

Tanto el art. 551.3 de la LOPJ, como la normativa local y la remisión que realiza el RGA, permiten la designación de un Abogado en ejercicio para la defensa de la Administración de la Ciudad si bien, a diferencia del criterio institucionalmente implantado y que más que ayudar a resolver problemas los terminó creando, la posibilidad se debe entender como subsidiaria de manera que la externalización sea la excepción y en ningún caso, la regla general ${ }^{19}$.

Avalando lo anterior, podemos citar, entre otras, la Sentencia del Tribunal Supremo de 14 de junio de 1994: "El Real Decreto de 18 de abril de 1.986, en su artículo 54, establece que la representación y defensa de los Entes locales se regirá por lo dispuesto en la Ley Orgánica del Poder Judicial. Esta, en su artículo 447.2. ${ }^{\circ}$, autoriza la representa-

18 BOME $n^{\circ} 4867$ de 8 de Noviembre de 2011

19 La normativa incorpora expresiones que parece orientarse en ese sentido como "corresponderá", "salvo que" y "sin perjuicio de". 
ción de los Entes locales a través de los letrados integrados en los servicios jurídicos del Estado, esto es, los Abogados del Estado, en los términos que reglamentariamente se establecerán, pero también permite que acudan al juicio bajo representación de Procurador y asistidos de Letrado designado por la corporación".

Igualmente el Decreto del Juzgado Contencioso $\mathrm{n}^{\circ} 3$ de Melilla recaída en el Procedimiento Abreviado 140/2013 recogió las diversas opciones que cuentan las administraciones públicas locales, entre ellas la Ciudad Autónoma, para ejercer su representación y defensa procesal, reconociendo expresamente a los "Abogados colegiados que designen".

El abogado por el que se opte no debe estar obligatoriamente colegiado en la Ciudad Autónoma a tenor de la Ley 25/2009, de 22 de diciembre, de modificación de diversas leyes para su adaptación a la Ley sobre el libre acceso a las actividades de servicios y su ejercicio por el que se modificó el art. 3.3 de la Ley 2/1974, de 13 de febrero de Colegios Profesionales de manera que "Cuando una profesión se organice por colegios territoriales, bastará la incorporación a uno solo de ellos, que será el del domicilio profesional único o principal, para ejercer en todo el territorio español".

Por todo ello, la defensa en juicio de los intereses de la Administración melillense puede encomendarse a un abogado ajeno a su Servicio Jurídico, si bien, debe optarse preferentemente por el encargo de los asuntos a los letrados propios, decantándose por abogados externos sólo de forma accesoria y excepcional y a través, como veremos, de la adecuada relación contractual.

\section{4) Otros supuestos de representación y defensa}

Una opción alternativa consiste en la habilitación por el órgano competente para el ejercicio de las acciones judiciales, esto es el Consejo de Gobierno, de un funcionario propio de la Administración Pública, Licenciado en Derecho, que no ocupe un puesto de trabajo específico de Letrado o Asesor Jurídico.

El Decreto del Juzgado Contencioso $\mathrm{n}^{\circ} 3$ de Melilla recaída en el Procedimiento Abreviado 140/2013 al determinar las diferentes alternativas que cuentan las entidades locales de ejercer su representación y defensa procesal, concluyó que, además de las recogidas en los apartados anteriores, con carácter excepcional podría designarse a un funcionario del Ente local que fuera licenciado en Derecho. Esta posibilidad fue objeto de una motivación específica en el fundamento juridico segundo en los siguientes términos: 
"La CAM para el ejercicio de su defensa ha manifestado una voluntad inequívoca de encargar la misma a un funcionario de la Consejería de Administraciones Públicas que fue la afectada por el primitivo recurso contencioso, al aceptar la propuesta de los Servicios Jurídicos de la CAM de 20 de abril de 2013 "de designar a tal efecto a los Letrados (debe entenderse funcionarios licenciados en derecho, no en el término técnico de la expresión, puesto que es de suponer que los Servicios Jurídicos tendrían conocimiento que no existen Letrados como tales en las Consejerías) de la Consejería de Administraciones Públicas y, entre tales licenciado en Derecho, está el Sr. G.A.

Ni la parte actora, ni este Secretario puede suplantar la voluntad de la CAM de utilizar un sistema de representación y defensa permitido, aunque sea de forma excepcional por la ley y la vigilancia en el cumplimiento del principio de legalidad que debe regir toda actuación de la Administración Pública en la forma solicitada, rebasa con exceso los límites del recurso de reposición y las funciones de este secretario."

Además, habría que hacer referencia, en el ámbito administrativo, al recurso previsto en el art. 54.4 de la Ley 29/1998, de 13 de julio, reguladora de la Jurisdicción Contencioso Administrativa y que permite que la Ciudad traslade, sin necesidad de abogado alguno, un escrito expresando los fundamentos por los que estime improcedente la pretensión ${ }^{20}$.

\section{NATURALEZA JURÍDICA DE LA CONTRATACIÓN DE UN LETRADO EXTERNO POR PARTE DE LA CIUDAD AUTÓNOMA DE MELILLA}

Una vez justificada la legalidad de la posible designación de abogados externos, se debe concretar su naturaleza jurídica como punto de partida para conocer posteriormente el procedimiento adecuado a seguir. En este aspecto, entramos en la tradicional problemática, con especial relieve en Melilla, de determinar si las contrataciones para la defensa en juicio de la Administración tienen el carácter de administrativos, regulados actualmente por la vigente Ley 9/2017, de 8 de noviembre, Contratos del Sector Público por la que se trasponen al ordenamiento jurídico español las Directivas del Parlamento Europeo y del Consejo 2014/23/UE y 2014/24/UE, de 26 de febrero de 2015 (en adelante LCSP) o, si por el contrario, son

20 Art. 54.4 de la LJCA: Si la Administración demandada fuere una entidad local y no se hubiere personado en el proceso pese a haber sido emplazada, se le dará no obstante traslado de la demanda para que, en el plazo de veinte días, pueda designar representante en juicio o comunicar al órgano judicial, por escrito, los fundamentos por los que estimare improcedente la pretensión del actor. 
contratos privados de arrendamiento de servicios del artículo 1544 del Código Civil.

Esta confusión fue avalada por la Audiencia Provincial de Melilla en el fundamento de derecho tercero de su Auto de 22 de marzo de 1999: "Si bien el artículo 3 de la Ley de Contratos del Estado no se excluye de la contratación administrativa la de servicios de abogados ajenos a sus plantillas por parte de las administraciones locales por estar referido su apartado $1^{\circ}$ solamente a la función pública y a la contratación laboral, al no presentar contornos pacíficos la posibilidad e imposibilidad de que tal contratación pueda ser enmarcada en el arrendamiento de servicios de los artículos 1544 y concordantes del Código Civil o el artículo 201 de aquel otro cuerpo legal, trabajos específicos y concretos no habituales, por el mismo principio de represión o reacción residual, ha de remitirse asimismo su dilucidación a aquel otro orden jurisdiccional con las eventuales consecuencias reparadoras o de resarcimiento que haya lugar".

Manteniendo las dudas interpretativas de la cuestión, el propio Tribunal Supremo en su Auto 597/2015 excluyó la existencia de prevaricación, malversación de caudales públicos y fraude a la Administración por parte del Presidente de la Ciudad Autónoma en la contratación de un letrado sin expediente de contratación administrativa alguno al tratarse de una cuestión que planteaba a juicio de la Sala "discrepancias interpretativas" y "disparidad de criterios": "En consecuencia, de la declaración del aforado y de los documentos presentados se deduce que la iniciativa para la designación del letrado no surgió de él, sino de uno de los consejeros de la Ciudad Autónoma; y que existen dudas interpretativas sobre la naturaleza del contrato que unía al letrado con la Ciudad Autónoma y, por tanto, si era necesario o no tramitar el correspondiente procedimiento administrativo de contratación. Mientras que la exposición razonada considera que estamos ante un contrato administrativo, el aforado entiende que nos hallamos ante un contrato de naturaleza civil de arrendamiento de servicios. Precisamente, varios documentos de los aportados a la causa versan sobre la naturaleza del contrato: Informe emitido por el Interventor Territorial de Melilla y el Interventor Territorial Adjunto de Melilla (folios 94 a 121 del Rollo de Sala), Informe del Secretario General de la Ciudad Autónoma de Melilla (folios 187 a 192), Informe del Secretario General de la Asamblea de Melilla de 9 de marzo de 2015, aportado por el aforado en su declaración....

En el presente supuesto no cabe apreciar una contradicción patente y grosera con el Derecho, basada en la omisión palmaria de los trámites procedimentales referidos a un contrato específico; en la medida en 
que se discute y existen discrepancias interpretativas sobre cuál era la naturaleza del contrato que se suscribió. Esto es, si existen discrepancias sobre cuál era la naturaleza del contrato, también existirán sobre cuáles eran los trámites procedimentales que se debían seguir, lo que impide hablar de una ilegalidad evidente flagrante y clamorosa o de una desviación o torcimiento del derecho, por cuanto era discutido qué normas jurídicas se debían aplicar al citado contrato. No corresponde a esta sala determinar cuál es la naturaleza del contrato y el procedimiento que debió seguirse, ya que no es la jurisdicción competente, pero sí es factible afirmar que precisamente la disparidad de criterios sobre normas jurídicas y procedimiento aplicable elimina los indicios de una posible prevaricación".

La postura seguida por el Presidente se encontraba amparado por el criterio institucional mantenido por la Ciudad y avalado por su Servicio Jurídico ${ }^{21}$ a tenor del cual se entendía que la relación entre la Administración melillense y el Abogado es de naturaleza exclusivamente civil teniendo el carácter de Arrendamiento de Servicios que debía limitarse a contar con los siguientes requisitos:

- Acuerdos corporativos adoptados por los órganos competentes para promover las acciones judiciales correspondientes

- Orden de pago acordada por órgano competente

- Mandamiento de pago intervenido en legal forma.

En este aspecto la Ciudad sustentaba el criterio de excluir la normativa contractual de naturaleza administrativa en cuanto a "que la Ley Orgánica del Poder Judicial, utiliza el infinitivo DESIGNAR cuando se refiere a Letrados Colegiados ajenos a la Administración para que representen y defiendan a las Comunidades Autónomas y a los Entes Locales, de significado distinto al de CONTRATAR"22.

Respetando la opinión precitada, el concepto de designación, tanto jurídica como gramaticalmente, supone señalar o destinar a una persona para un determinado fin, en este caso, la representación y defensa a cambio de unos honorarios, generando efectos jurídicos tanto para la Ciudad que debe asumir el pago de un precio, como para el letrado externo que asume la responsabilidad encomendada de defensa y representación de la Administración melillense, estableciéndose una vinculación jurídica contractual, cuya

21 Informes de 26 de Enero de 2012, 28 de Febrero de 2014 y de 12 de diciembre de 2016

22 Informe de 26 de Enero de 2012, Página 5. 
naturaleza deberá determinarse aclarando si debe calificarse como administrativa o privada.

A mi juicio, y reconociendo el carácter conflictivo de la cuestión que continúa siendo debatido por la doctrina, las contrataciones llevadas a cabo entre la Ciudad Autónoma y abogados en ejercicio, bajo la vigencia de la actual LCSP, merecen la consideración de contratos de naturaleza administrativa de servicios a tenor de la propia definición que establece el artículo 17: "aquellos cuyo objeto son prestaciones de hacer consistentes en el desarrollo de una actividad o dirigidas a la obtención de un resultado distinto de una obra o un suministro, incluyendo aquellos en que el adjudicatario se obligue a ejecutar el servicio de forma sucesiva y por precio unitario. No podrán ser objeto de estos contratos los servicios que impliquen ejercicio de la autoridad inherente a los poderes públicos.

Es cierto que la Directiva 2014/24/UE excluye de su ámbito de aplicación en su art. 10.d ${ }^{23}$ determinados servicios jurídicos, no obstante tal disposición carece de efectos directos al excluirse por la jurisprudencia del Tribunal de Justicia de la Unión Europea la aplicación de normas no transpuestas al Derecho nacional en perjuicio de los particulares, de modo que los poderes adjudicadores no pueden acogerse al efecto directo de los preceptos no traspuestos que les permitan, por ejemplo, exceptuar de la licitación con publicidad y concurrencia ciertos tipos de contratos como los recogidos en el artículo 10.d) ${ }^{24}$ de la Directiva 2014/24, de contratación pública, referida a ciertos servicios jurídicos.

23 El considerando 25 de la Directiva 2014/24/UE, justifica la exclusión a la que se refiere el art. 10.d en los siguientes términos: "Determinados servicios jurídicos son facilitados por proveedores de servicios nombrados por un tribunal o un órgano jurisdiccional de un Estado miembro, implican la representación de clientes en un proceso judicial por abogados, deben ser prestados por notarios o guardar relación con el ejercicio de una autoridad oficial. Dichos servicios jurídicos son prestados normalmente por organismos o personas nombrados o seleccionados mediante un procedimiento que no puede regirse por las normas de adjudicación de los contratos, como ocurre por ejemplo, en algunos Estados miembros, con el nombramiento del ministerio fiscal. Por consiguiente, estos servicios jurídicos deben quedar excluidos del ámbito de aplicación de la presente Directiva.»

24 I) representación legal de un cliente por un abogado, en el sentido del artículo 1 de la Directiva 77/249/CEE del Consejo (Considerando 25) en:

- un arbitraje o una conciliación celebrada en un Estado miembro, un tercer país o ante una instancia internacional de conciliación o arbitraje, o

- un procedimiento judicial ante los órganos jurisdiccionales o las autoridades públicas de un Estado miembro, un tercer país o ante órganos jurisdiccionales o instituciones internacionales.

II) asesoramiento jurídico prestado como preparación de uno de los procedimientos mencionados en el inciso I) de la presente letra, o cuando haya una

(C) UNED. Revista de Derecho UNED, núm. 27, 2021 
En consecuencia, en tanto no se incorporen las novedades que introduce la Directiva 2014/24/UE, los contratos de servicios jurídicos incluidos en su ámbito de aplicación deberían respetar las reglas y procedimientos de la LCSP, sin que pueda considerase que, en ausencia de transposición formal, dichos contratos se encuentran excluidos o sometidos a ningún régimen especial ${ }^{25}$.

La línea argumental expuesta supone que queden incorporados y sometidos a las previsiones de la LCSP los servicios jurídicos que la Directiva 2014/24/UE excluía de forma expresa en el art. 10.d), constituyendo uno de los contratos típicos del sector público al recogerse expresamente tanto en el Anexo XIV de la Directiva 2014/24/UE del Parlamento Europeo y del Consejo de 26 de febrero de 2014, como en el Anexo II del derogado Real Decreto Legislativo 3/2011, de 14 de noviembre, por el que se aprueba el texto refundido dela Ley de Contratos del Sector Público ${ }^{26}$ dentro de la categoría 21 y, actualmente como uno de los considerados como servicios específicos o especiales relacionados en el Anexo IV de la $\operatorname{LCSP}^{27}$.

indicación concreta y una alta probabilidad de que el asunto sobre el que se asesora será objeto de dichos procedimientos, siempre que el asesoramiento lo preste un abogado en el sentido del artículo 1 de la Directiva 77/249/CEE.

III) servicios de certificación y autenticación de documentos que deban ser prestados por un notario.

$I V)$ servicios jurídicos prestados por administradores, tutores $u$ otros servicios jurídicos cuyos proveedores sean designados por un órgano jurisdiccional en el Estado miembro en cuestión o designados por ley para desempeñar funciones específicas bajo la supervisión de dichos órganos jurisdiccionales.

$V)$ otros servicios jurídicos que en el Estado miembro de que se trate estén relacionados, incluso de forma ocasional, con el ejercicio del poder público.».

25 Exclusivamente y a tenor de la legislación estatal de aplicación, el art. 11.2 y 3 de la LCSP, con la denominación "Otros negocios y contratos excluidos», se excluyen del ámbito de aplicación de la norma, los siguientes servicios jurídicos:

“a) Las relaciones jurídicas consistentes en la prestación de un servicio público cuya utilización por los usuarios requiera el abono de una tarifa, tasa o precio público de aplicación general, es decir, los servicios jurídicos sometidos a arancel, y

b) Los contratos relativos a servicios de arbitraje y conciliación."

26 Especialmente relevante es el Informe 30/2012, de 7 de Mayo de 2012, referido a la "Calificación jurídica de los contratos entre el Ayuntamiento y un abogado", enmarcado en la normativa anterior pero cuyas consideraciones pueden hacerse extensivas, con matices, al ordenamiento vigente "Así, el contrato de servicios aparece definido en el artículo 10 del Texto Refundido de la Ley de Contratos del Sector Público, aprobado por Real Decreto Legislativo 3/2011, de 14 de noviembre, en adelante TRLCSP, que determina que son contratos de servicios aquellos cuyo objeto son prestaciones de hacer consistentes en el desarrollo de una actividad o dirigidas a la obtención de un resultado distinto de una obra o un suministro. A efectos de aplicación de esta Ley, los contratos de servicios se dividen en las categorías enumeradas en el Anexo II".

27 Dentro de esta categoría se incluyen una relación de servicios de muy diferente naturaleza y que el vocabulario común de contratos (CPV) aprobado por 
La inclusión de los servicios jurídicos como una especie de estos contratos resulta claramente de su mención expresa en el Anexo IV de la LCSP, pues si los servicios jurídicos no fuesen propios contratos administrativos de servicios carecería de sentido la mención a éstos expresamente, no debiendo quedar la naturaleza jurídica al arbitrio del órgano de contratación atendiendo al principio de legalidad que debe regir la actuación administrativa y que impone la necesidad que la misma se encuentre amparada por una norma habilitante que atribuya expresamente a la Administración Pública el ejercicio específico una potestad concreta.

Por todo ello, entiendo que la contratación de la Ciudad de su defensa jurídica constituye ciertamente un contrato administativo de servicios y, a pesar de su estrecho vínculo con el contrato de arrendamiento de servicios, no debe calificarse como civil por regla general, más aún si la propia LCSP los recoge expresamente como administrativos, como hemos visto.

Además, si bien la identidad de objeto entre los contratos administrativos y de arrendamiento de servicios de abogados es manifiesto en cuanto a la actividad a desarrollar, la vinculación directa al interés público en el ejercicio de defensa en juicio de la Administración por imperativo constitucional ${ }^{28}$ dentro del ámbito de las competencias encomendadas nos debe trasladar como opción, al menos preferente, a la vía de la contratación administrativa.

Una vez calificados los contratos de la Ciudad con abogados en ejercicio como administrativos de servicios, la determinación de su régimen jurídico no suscita dificultad alguna, dado que, a tenor de lo dispuesto en el artículo 25 de la LCSP se regirán en cuanto a su preparación, adjudicación, efectos y extinción, por esta Ley y sus disposiciones de desarrollo; supletoriamente se aplicarán las restantes normas de derecho administrativo y, en su defecto, las normas de derecho privado.

Por otro lado y planteándose si la distinción en cuanto a su naturaleza jurídica tiene incidencia alguna en cuanto a la limitación de la competencia entre profesionales y las presuntas irregularidades en las adjudicaciones de estas contrataciones, debe precisarse que

el Reglamento Núm. 213/2008, de la Comisión, de 28 de noviembre de 2007, califica en tres grandes subcategorías que encuadra en los códigos 79110000-8 a 791400007: Representación en juicio; Asesoría; y Documentación e información jurídicas.

${ }_{28}$ Art. 103.1 de la CE: "La Administración Pública sirve con objetividad los intereses generales y actúa de acuerdo con los principios de eficacia, jerarquía, descentralización, desconcentración y coordinación, con sometimiento pleno a la ley y al Derecho." 
no existe una distinción del régimen jurídico de los contratos privados de la Administración y los contratos administrativos en cuanto a la designación de los abogados, dado que en orden a su preparación y adjudicación, los contratos privados se rigen, al igual que los administrativos, por la Ley de Contratos del Sector Público y sus normas de desarrollo (art. 26.2 LCSP), de modo que la diferenciación entre contratos administrativos y privados de la Administración sólo tiene relevancia en cuanto a sus efectos, modificación y extinción, no siendo siquiera preciso calificar de uno u otro modo el contrato si se examina su preparación o adjudicación (STS 27 de junio de 1.977; 5 de octubre de 1.981; 26 de noviembre de 1.985; y 17 de noviembre de 1.986) como es el caso que se planteó en Melilla donde el conflicto derivaba de la supuesta vulneración de los principios de adjudicación legalemente establecidos.

Este criterio es el que se mantuvo por el Juzgado de Instrucción $\mathrm{n}^{\circ} 2$ de Melilla en su Auto 838/2011 que si bien acordó el archivo de las actuaciones penales por un presunto delito de prevaricación por parte de los Consejeros y el Presidente de la Ciudad Autónoma en la contratación de letrados externos en su Fundamento jurídico segundo advierte que "...la calificación del contrato como contratos administrativos o como contratos privados de arrendamiento de Servicios es intrascendente pues se aplican en todo caso los preceptos de la ley administrativa relativas a la preparación y adjudicación de los contratos de las Administraciones Públicas......En conclusión y en relación al tipo objetivo, este Juez, instructor considera, independientemente de la naturaleza jurídica del contrato, que existió una vulneración patente de la norma administrativa que era exigible en la fase de preparación y adjudicación de las contraciones de letrados externos...."

Por todo ello, tanto si consideramos estas contrataciones como administrativas, como si se les reconoce el carácter de contratos privados de arrendamientos de servicios, deberá respetarse el cumplimiento de la LCSP en cuanto a su preparación y adjudicación, por lo que no cabe la intervención de Abogado externo en defensa de los intereses de la Ciudad Autónoma al margen de los procedimientos previstos en la LCSP, sin que pueda admitirse la libre elección de profesionales privados, aún en el supuesto de que se hubiese otorgado por el Presidente de la Ciudad un poder para pleitos o se acordara expresamente por el Consejo de Gobierno.

Es cierto que el sistema de designación directa podría ser el más coherente con la relación que surge entre la Ciudad Autónoma y el letrado, una relación basada en la confianza como dispone el artículo 12.1 del Código Deontológico de la Abogacía Española y que 
obliga a éste último a actuar siempre diligentemente, con competencia, lealtad a la Administración en su condición de cliente y guardando el correspondiente sigilo profesional de cuanto conociere por razón de su profesión, pero esa argumentación debe ceder ante el principio de legalidad y de vinculación positiva del ejercicio de potestades de la Administración a la ley, lo que exige someterse a la tramitación de un expediente administrativo previo que garantice los principios de libertad de acceso a las licitaciones, publicidad y transparencia de los procedimientos, y no discriminación e igualdad de trato entre los licitadores, trámites que abordaremos en el siguiente apartado.

\section{ELEMENTOS RELEVANTES DEL PROCEDIMIENTO DE CONTRATACIÓN DE UN LETRADO EXTERNO POR PARTE DE LA CIUDAD AUTÓNOMA DE MELILLA}

\section{Primero.- COMPETENCIA PARA LA PREPARACIÓN DEL CONTRATO.}

El Título II del EA determina las competencias de la Ciudad de Melilla las cuales se distribuyen posteriormente entre las diferentes Consejerías de la Ciudad a través del Decreto de distribución de competencias que debe aprobar el Consejo de Gobierno al tomar posesión el Presidente o cuando se produzca alguna modificación de las estructuras de gobierno ${ }^{29}$.

Debe entenderse de conformidad con los sucesivos Decretos de Consejo de Gobierno por el que se distribuyen las competencias de la Ciudad entre las diferentes Consejerías, que corresponde a la Consejería competente por razón de materia objeto del conflicto judicial que requiera la externalización la preparación del contrato de servicio jurídico en virtud de las delegaciones efectuadas por la Consejera competente en materia de contratación de conformidad en el

29 Art. 68 del RGA: "1. El Presidente de la Ciudad Autónoma de Melilla, al tomar posesión de su cargo o cuando se produzca una modificación de las estructuras de gobierno, deberá proponer un Decreto en el que se establezcan las competencias que le correspondan a la Presidencia y a cada una de las diferentes Consejerías en las que se estructure en cada momento el Gobierno de la Ciudad Autónoma de Melilla. 2. El Decreto de distribución de competencias, que tendrá forma articulada, deberá contener, al menos, los siguientes aspectos: a) Denominación de las diferentes Consejerías. b) Competencias que le correspondan a cada Consejería. c) Estructura administrativa que le corresponda a cada Consejería, al menos hasta nivel de Direcciones Generales. 3. El Decreto de distribución de competencias se deberá publicar en el Boletín Oficial de la Ciudad de Melilla para su general conocimiento y efectos."

(C) UNED. Revista de Derecho UNED, núm. 27, 2021 
artículo 112.4 del $\mathrm{RGA}^{30}$ y las Disposiciones Adicionales Segunda y quincuagésima segunda de la LCSP debiendo asumir, por tanto, las siguientes actuaciones:

- Orden de inicio del procedimiento de contratación, motivando la necesidad del contrato.

- Pliegos de cláusulas administrativas particulares y de prescripciones técnicas que hayan de regir el contrato.

- Solicitud e incorporación al expediente del certificado de existencia de crédito o documento que legalmente le sustituya.

- Justificación de la elección del procedimiento y la de los criterios que se tendrán en consideración para adjudicar el contrato.

- Incorporación del resto de actuaciones y trámites que sean necesarios con carácter previo a la aprobación del expediente de contratación.

En el supuesto de que se admitiera la posibilidad de llevar a cabo una contratación menor, lo que plantea cierta problemática, conforme a lo dispuesto en el artículo 112.6 del RGA, son órganos de contratación en los contratos menores los respectivos Consejeros como titulares superiores de cada una de las Consejerías correspondiendo, por tanto, al titular de la Consejería que tenga encomendadas las competencias objeto del litigio asumir las potestades propias del órgano de contratación y cumplir con lo previsto en el art. 118 de la $\operatorname{LCSP}^{31}$.

30 Art. 112.4 del RGA: "No obstante lo anterior, la Consejería competente en materia de contratación administrativa podrá delegar en el resto de Consejerías, según les correspondan en virtud del objeto del contrato y de su área de competencia, la iniciación del expediente de contratación y la realización de actuaciones comprendidas en las fases de preparación y de ejecución de los contratos, conforme a lo establecido en la legislación de contratos del Sector Público y en la legislación estatal básica en materia de delegación de competencias".

31 Art. 118 de la LCSP: "1. Se consideran contratos menores los contratos de valor estimado inferior a 40.000 euros, cuando se trate de contratos de obras, o a 15.000 euros, cuando se trate de contratos de suministro o de servicios, sin perjuicio de lo dispuesto en el artículo 229 en relación con las obras, servicios y suministros centralizados en el ámbito estatal.

2. En los contratos menores la tramitación del expediente exigirá la emisión de un informe del órgano de contratación justificando de manera motivada la necesidad del contrato y que no se está alterando su objeto con el fin de evitar la aplicación de los umbrales descritos en el apartado anterior.

3. Asimismo se requerirá la aprobación del gasto y la incorporación al mismo de la factura correspondiente, que deberá reunir los requisitos que las normas de desarrollo de esta Ley establezcan. 
En cualquier caso, es evidente que la contratación del letrado externo exige la previa conformación de un expediente entendido como conjunto de actuaciones internas anteriores a la correspondiente convocatoria de licitadores o adjudicación directa en el supuesto de contratación menor.

\section{Segundo.- EJERCICIO DE LA ACCIÓN JUDICIAL Y DEFENSA}

De manera paralela a la contratación administrativa debe tramitarse un expediente administrativo de ejercicio de la acción judicial atendiendo al artículo 68 de la LBRL que establece la obligación que tienen los entes locales "de ejercer las acciones necesarias para la defensa de sus bienes y derechos" previsión que ha de entenderse, en este caso, referida no sólo a la iniciativa en cuanto al planteamiento de acciones judiciales, sino igualmente a la defensa de los intereses de la respectiva corporación frente a las pretensiones que en vía jurisdiccional puedan plantear los particulares u otras administraciones públicas.

Esta obligación incumbe al Pleno municipal, por mandato de los artículos 22.2 j) de la LBRL, $23.1 \mathrm{f}$ ) del TRRL y 50.17 del ROF, expresado en el sentido de que le corresponde "El ejercicio de acciones judiciales y administrativas y la defensa de la corporación en materias de competencia plenaria", precepto que ha de completarse con el cometido que confiere al Alcalde el artículo $21.1 \mathrm{k}$ ) de la LBRL, al que atribuye competencia para el "ejercicio de las acciones judiciales y administrativas y la defensa del ayuntamiento en las materias de su competencia, incluso cuando las hubiere delegado en otro órgano, y, en caso de urgencia, en materias de la competencia del Pleno, en este supuesto dando cuenta al mismo en la primera sesión que celebre para su ratificación".

4. En el contrato menor de obras, deberá añadirse, además, el presupuesto de las obras, sin perjuicio de que deba existir el correspondiente proyecto cuando sea requerido por las disposiciones vigentes. Deberá igualmente solicitarse el informe de las oficinas o unidades de supervisión a que se refiere el artículo 235 cuando el trabajo afecte a la estabilidad, seguridad o estanqueidad de la obra.

5. Lo dispuesto en el apartado $2 .^{\circ}$ de este artículo no será de aplicación en aquellos contratos cuyo pago se verifique a través del sistema de anticipos de caja fija u otro similar para realizar pagos menores, siempre y cuando el valor estimado del contrato no exceda de 5.000 euros. 63.4."

6. Los contratos menores se publicarán en la forma prevista en el artículo 
En el ámbito jurídico de la Ciudad,y por la remisión que realiza el artículo 30 del Estatuto de Autonomía de Melilla al régimen local, estas competencias corresponden al Pleno de la Asamblea (12.2 del EA) y al Presidente de la Ciudad por su condición de Alcalde ${ }^{32}$, competencias, ambas dos, que fueron delegadas al Consejo de Gobierno mediante Acuerdo de la Asamblea de Melilla 28 de junio de 1995 y el Decreto de Presidencia número 31 de 31 de marzo del año 2000. Por ello, es el Consejo de Gobierno de la Ciudad el encargado, por delegación ${ }^{33}$, de acordar el inicio de las acciones judiciales pertinentes y encomendar la dirección técnica de los procedimientos a los correspondientes letrados.

En relación a la existencia de informe previo, el ejercicio de acciones judiciales en calidad de "actor" por las Entidades locales requieren a tenor del artículo 54.3 del TRRL el "previo dictamen del Secretario, o, en su caso, de la Asesoría Jurídica y, en defecto de ambos, de un Letrado". El Consejo de Gobierno en sesión de 20 de febrero de 2004 (BOME número 4064, de 27 de febrero de 2004) acordó que para el ejercicio de las acciones judiciales el dictamen previo podría evacuarse por la Asesoría Jurídica, la Secretaría Técnica de la correspondiente Consejería o un Letrado de la misma,

Por ello, no es necesario el correspondiente dictamen cuando la Administración se encuentre en la posición demandada por no exigirlo expresamente ni el TRRL, ni el artículo 221.1 del ROF que sólo hacen referencia literal al "ejercicio de acciones".

Así lo ha entendido la Jurisprudencia señalando que el dictamen se requiere cuando las Entidades locales ejerciten acciones, pero no cuando se trate de mera defensa de las demandas presentadas contra ellas como confirmó la Sentencia del Tribunal Supremo de 14 de junio de 1994:"El artículo 54.3 del mismo Decreto de 18-IV-86 establece que el Ayuntamiento para ejercitar acciones necesita informe del Secretario previo al acuerdo municipal. Los poderes los otorga el Alcalde y éste tiene incluso facultades en virtud del artículo 40 del R.D. 28 de noviembre de 1986 para ejercer acciones dando cuenta al Pleno

32 Art. 10.1 ñ) del RGA: "Corresponde al Presidente de la Ciudad Autónoma de Melilla"Ejercer las acciones judiciales y administrativas y la defensa de la Ciudad en aquellas materias que no sean competencia del Pleno de la Asamblea, sin perjuicio de su delegación en el Consejo de Gobierno. Asimismo le corresponde el ejercicio de las acciones judiciales y administrativas en materia de competencia del Pleno de la Asamblea en los supuestos de urgencia, dando cuenta, en este último supuesto, al citado órgano en la primera sesión que celebre para su ratificación".

33 Art. 16.1.26 del RGA: "Al Consejo de Gobierno le corresponde: El ejercicio de acciones judiciales y administrativas y la defensa de la Ciudad, cuando así se lo hubiere delegado el Presidente y la Asamblea." 
por razones de urgencia. Pero nada dice sobre la obligatoriedad de dicho informe cuando no ejercita acciones sino que se defiende de las que contra el Ayuntamiento se dirigen y, en consecuencia, no cabe extender una norma restrictiva a supuestos no expresamente contemplados".

Posteriormente, y con el mismo criterio, la Sentencia del Tribunal Supremo de 30 de noviembre de 1995 determinó que "La exigencia contenida en el artículo 54.3 del Texto Refundido de Régimen Local de 18 de abril de 1986 y el 221.1 del Reglamento de organización, funcionamiento y régimen jurídico de las corporaciones locales viene referida única y exclusivamente para el ejercicio de acciones a deducir por los Entes Locales, lo que desde luego no incluye la personación y defensa realizadas por éstos de sus propias resoluciones y acuerdos, ante los órganos jurisdiccionales, cuando son impugnados en dicha sede por terceros interesados. Tal doctrina ha sido reiteradamente expuesta por esta Sala, ya contenida en Sentencias como las de 3 de octubre de 1966, 6 de diciembre de 19676 y 22 de enero de 1971 donde se afirma categóricamente que el requisito del previo dictamen del Secretario, Asesoría o Letrado exigidos por el artículo 54.3 del Texto Refundido de Régimen Local de 18 de abril de 1986 y el 221.1 del Reglamento de organización, funcionamiento y régimen jurídico de las corporaciones locales, se refiere al caso de que las Entidades locales ejerciten acciones, pero no cuando se trate de mera defensa de las demandas presentadas contra ellas".

\section{Tercero.- OBJETO DEL CONTRATO.}

En cuanto a las prestaciones que puede incluir el objeto del contrato de servicios jurídicos el art. 99 LCSP exige que éste sea determinado y que no pueda fraccionarse con la finalidad de disminuir la cuantía del mismo y eludir así los requisitos de publicidad o los relativos al procedimiento de adjudicación que correspondan y, además, siempre que sea posible, deberá preverse la realización independiente de cada una de sus partes mediante su división en lotes.

La concreción del objeto de las prestaciones a realizar en los supuestos de defensa y representación en juicio puede resultar complejo a efectos de determinar su contenido y duración en la fase preparativa de la contratación, pudiendo incorporar actuaciones e intervenciones diversas ante cualquiera de los órdenes jurisdiccionales, ya sea en su ámbito natural que es el contencioso-administrativo, como ante la Jurisdicción Social, Civil, Mercantil o Penal.

Admitiendo esa dificultad de determinación previa, el objeto del contrato de servicios jurídicos debe quedar fijado en los pliegos de 
cláusulas administrativas y de prescripciones técnicas con el fin de otorgar la mayor seguridad jurídica posible al principio de competencia que debe regir en la adjudicación de la licitación debiendo los letrados concurrentes conocer la extensión y el alcance de las necesidades que demanda la Administración, siendo definidas con carácter previo y evitando alusiones genéricas o confusas.

A lo anterior habrá que añadir la dificultad que tendrá el coordinar los tiempos de la tramitación de la contratación de un letrado externo con los plazos otorgados por los órganos jurisdiccionales a efectos de evitar el incumplimiento de plazos en los procesos judiciales con repercusiones negativas para la defensa de los intereses públicos y generales.

\section{Cuarto.- JUSTIFICACIÓN DE LA NECESIDAD E IDONEIDAD DEL CONTRATO.}

El art. 28 de la LCSP exige que las entidades del sector público no puedan celebrar otros contratos que aquellos que sean necesarios para el cumplimiento y realización de sus fines institucionales por lo que la naturaleza y extensión de las necesidades que pretenden cubrirse, así como la idoneidad del objeto y contenido para satisfacerlas, deben ser determinadas con precisión, dejando constancia de ello en la documentación preparatoria, antes de iniciar el procedimiento encaminado a su adjudicación.

De esta manera y conjugando el precitado art. 28 de la LCSP con el 551.3 de la LOPJ la contratación de letrados externos llevada a cabo por la Ciudad es un recurso al que debe acudirse de manera subsidiaria, siendo necesario que por la Consejería competente en relación a la fase de preparación del contrato justifique debidamente la insuficiencia de medios, la falta de adecuación o conveniencia de acometer esa externalización.

Al encuadrar la designación de abogados externos en el ámbito de la contratación administrativa de servicios el art. 116.4 f) de la LCSP exige la incorporación del "informe de insuficiencia de medios", pues como impone el art. 30.3 la prestación de servicios debe hacerse normalmente por la Administración por sus propios medios solo pudiendo acudir a la externalización cuando carezca de los mismos y previa justificación en el expediente.

La existencia del Servicio Jurídico de la Ciudad, impuesta con carácter preceptivo por el art. 96 del RGA, exige que la contratación de 
abogados externos para la defensa en juicio de la Administración se motive expresamente, no bastando con un informe tipo del propio Servicio jurídico que proponga la acción judicial sino con una motivación expresa que acredite la ausencia de especialización de los Letrados propios frente a determinadas materias o la sobrecarga de trabajo de los abogados internos de la Ciudad.

\section{Quinto.- DELIMITACIÓN DEL CONTRATO DE SERVICIOS JURÍDICOS RESPECTO A LA PRESUNCIÓN DE LABORALIDAD}

El art. 308.2 de la LCSP pretende impedir el uso fraudulento de la contratación administrativa como medio de encubrimiento de auténticas relaciones laborales, prohibiendo tanto el nacimiento como la consolidación de aquellas personas que efectúen las prestaciones propias del servicio jurídico contratado:

"En ningún caso la entidad contratante podrá instrumentar la contratación de personal a través del contrato de servicios, incluidos los que por razón de la cuantía se tramiten como contratos menores.

A la extinción de los contratos de servicios, no podrá producirse en ningún caso la consolidación de las personas que hayan realizado los trabajos objeto del contrato como personal de la entidad contratante. A tal fin, los empleados o responsables de la Administración deben abstenerse de realizar actos que impliquen el ejercicio de facultades que, como parte de la relación jurídico laboral, le corresponden a la empresa contratista."

Como hemos visto el contrato administrativo de servicios jurídicos tiene un objeto de tal amplitud que sus tareas pueden coincidir con las funciones asumidas por un abogado contratado laboralmente con los posibles riesgos de encontrarnos con resoluciones judiciales que ante la figura de los llamados falsos autónomos terminen declarando como personal laboral no fijo de plantilla a quienes fueron contratados fraudulentamente bajo el paraguas del contrato administrativo.

Especialmente relevante en este sentido fue la Sentencia ${ }^{\circ}$ 39/2016 del Juzgado de lo Social de Melilla en el que si bien se refiere a la laboralidad de un contrato privado de arrendamientos de servicios de un Letrado, sus fundamentos son plenamente extensibles al supuesto de que nos hubiésemos encontrado ante un contrato administrativo de servicios jurídicos:

"Dependencia en cuanto que inserción en el círculo organizativo y disciplinario del empresario que igualmente concurre en el caso del 
actor, habida cuenta de su inclusión en el Gabinete Jurídico dentro de los servicios administrativos de la Presidencia de la Ciudad Autónoma como se hace constar en hechos probados y atendiendo preeminentemente a la declaración del Jefe de los Servicios jurídicos de la Ciudad autónoma, que con conocimiento directo del contenido de la prestación de servicios del actor, fue taxativo al indicar que ésta se realizaba atendiendo a la recepción de instrucciones por parte de la Ciudad Autónoma, incluso provenientes directamente del Presidente de la misma. Circunstancia a la que añadir la acreditación igualmente por ambas testificales practicadas, y por los partes de control unidos a las actuaciones, de la sujeción del actor a un horario; así como disfrute anual de periodo anual de vacaciones retribuidas y permisos, bajo el visto bueno del Jefe de los Servicios jurídicos; la utilización de los medios de la empleadora tales como despacho profesional propio en sus dependencias, medios informáticos, tarjetas de identificación electrónica y cuentas de correo electrónico de la ciudad autónoma, en los términos propiamente constatados en el informe del Director General de la sociedad de la Información de la CAM....

Finalmente por lo que a la retribución se refiere, queda plenamente acreditado que ésta consistía en una cantidad regular por doce mensualidades y dos retribuciones extraordinarias en Junio y diciembre, y que al margen de la denominación recogida, su verdadera naturaleza es la del salario de un trabajador y no la de honorarios de un profesional liberal.

Resultando de lo anterior que la prestación de servicios del actor como Letrado para la ciudad autónoma desde la fecha reseñada de 16 de abril de 1997, con despacho propio asignado en los propios Servicios Jurídicos de la CAM, con los medios materiales y profesionales facilitados por la Administración para su uso, bajo el respeto de un horario de entrada y salida preestablecido al igual que el personal funcionario, con disfrute anual de vacaciones retribuidas y abono de dos pagas extraordinarias anuales, siendo su actuación limitada a lo manifestado a criterio de dicha entidad siguiendo las directrices de ésta en cada caso como Letrado director y estando integrado física, estructural, orgánica y funcionalmente en el Gabinete Jurídico de Presidencia ha de ser calificada, atendiendo al contenido de los artículos 1, 8 y 15 del ET, como relación laboral con carácter indefinido no fijo de plantilla de la Ciudad Autónoma de Melilla....."

Es necesario por tanto, acreditar en el expediente de contratación de manera expresa que la relación en ningún caso es de naturaleza laboral y que la función de defensa en juicio se llevará a cabo por el adjudicatario con sus propios medios debiendo evitarse en la ejecución del contrato conductas propias de la relación laboral como la implantación de una retribución periódica asimilada al salario, la fijación de un horario, el desempeño de las funciones en edificios de la Ciudad o la disponibilidad de equipos electrónicos de la Administración 


\section{Sexto.- DURACIÓN DEL CONTRATO DE SERVICIOS JURÍDICOS}

La duración máxima de los contratos de servicios, también de los jurídicos, se encuentra limitada a cinco años, incluyendo las posibles prórrogas que el órgano de contratación pudiera acordar respetando las condiciones y límites establecidos en las respectivas normas presupuestarias que sean aplicables al órgano contratante ${ }^{34}$. Por su parte, los contratos menores definidos en el art. 118 dela LCSP no podrán tener una duración superior a un año ni ser objeto de prórroga.

La duración debe establecerse teniendo en cuenta la naturaleza de las prestaciones, las características de su financiación y la necesidad de someter periódicamente a concurrencia su realización, así como la necesidad de que el expediente se refiera a la totalidad de su objeto.

Es de resaltar que se ha eliminado en la LCSP la referencia expresa, como hacía el art. 303.3 del TRLCSP, a la posibilidad de que los contratos para la defensa jurídica y judicial de la Administración tuvieran la duración precisa para atender adecuadamente sus necesidades, por lo que es imprescindible determinar de forma previa y concreta la naturaleza y la extensión de las necesidades que pretenden cubrirse mediante el contrato de servicios proyectado, así como la idoneidad de su objeto y contenido para satisfacerlas, dando cumplimiento a la obligación impuesta por el, ya comentado, art. 99 de la LCSP.

La dificultad para determinar la duración de estos contratos viene dada por la complejidad de la defensa jurídica y judicial, y por la limitación que supone la prohibición de fraccionamiento del contrato, tal y como determinó la Junta de Consultiva de Contratación Administrativa mediante Informe 30/12, de 7 de mayo de 2012 referente a la "Calificación jurídica de los contratos entre el Ayuntamiento y un abogado":

"A tenor de este artículo no parece apropiado celebrar un contrato para cada uno de los juicios que tenga el Ayuntamiento sino que debería hacerse un contrato que englobase todos los juicios en que participe en un periodo de tiempo determinado. Así, el objeto del contrato es la asistencia en juicio de la entidad, sin que sea correcto afirmar que tal objeto pueda ser cada uno de los juicios celebrados, máxime cuando todos ellos se adjudican al mismo abogado. Existe así una unidad en las necesidad que se satisface con este contrato, una sola prestación y un solo servicio a cumplir, como es la defensa jurídica del Ayuntamiento, por lo que apreciar que cada juicio puede consti-

34 Art. 29 de la LCSP

(C) UNED. Revista de Derecho UNED, núm. 27, 2021 
tuir un objeto supondría una ruptura no justificada del objeto del contrato. En este sentido, debemos tener en cuenta que el propio texto de la consulta explica que la representación del Ayuntamiento de Paiporta en juicio no es ocasional o esporádica sino que se da de manera regular y continuada en el tiempo, así resulta del propio texto cuando dice: "Debido a la elevada litigiosidad que afecta a esta Corporación, la suma anual de los honorarios del Abogado que normalmente la defiende en juicio supera los limites cuantitativos del contrato menor, y aún del negociado sin publicidad (el año 2010 este Abogado intervino en más de treinta juicios y devengó unos honorarios totales por ello de ochenta y nueve mil euros, y el 2011 actuó en más de quince procesos, con unos honorarios totales de cuarenta y nueve mil euros)." Debemos considerar aqui que existe una unidad de carácter funcional que sería la defensa genérica del Ayuntamiento en juicio (excluyendo aquellos procesos jurisdiccionales en los que la representación corresponda a los abogados de la compañía aseguradora del Consistorio), lo que exige celebrar un único contrato de defensa judicial del Ayuntamiento y no uno por cada juicio que se celebre".

En Melilla, y con gran trascendencia en relación a esa prohibición del fraccionamiento, la Sentencia de la Audiencia Provincial 1/2019, de 11 de Enero de 2019, respecto a la contratación reiterada de abogados mediante la modalidad de contratación menor dispuso que:

" $1^{\circ}$.-Se fraccionó el importe del contrato que es ajustado al límite cuantitativo del contrato menor y se acomodó la duración temporal de los contratos al límite de seis meses, pese a la naturaleza estructural y dotada de permanencia en el tiempo de la actividad.

$2^{\circ}$.-Se prescindió de los principios de publicidad y libre concurrencia que deben estar presentes en la contratación administrativa.

$3^{\circ}$.-Los servicios de asesoramiento fueron siempre otorgados a favor de los mismos profesionales elegidos, durante 10 años en unos casos y 5 años en otro.

De este modo, el proceso de contratación descrito infringe la normativa administrativa sobre contratación pública. La ilegalidad del procedimiento de contratación de los servicios de asistencia técnicojurídica tenía lugar mediante el fraccionamiento indebido de una actividad por naturaleza permanente y estructural del organismo que contrataba, a través de la utilización reiterada e ilegal del procedimiento correspondiente a los contratos menores, tanto por la cuantía, como por su duración, que determinaba en la realidad la 
omisión de todo proceso selectivo para la cobertura de las plazas mediante concurso público, con quiebra de los principios de publicidad, concurrencia, transparencia, igualdad y libertad de acceso. Práctica que se extendió durante más de diez años ininterrumpidos en el caso de tres Letrados y cinco en el caso de un cuarto.

La omisión del procedimiento legalmente establecido ha sido considerada como una de las razones que pueden dar lugar a la calificación delictiva de los hechos, porque las pautas establecidas para la tramitación del procedimiento a seguir en cada caso tienen la función de alejar los peligros de la arbitrariedad y la contradicción con el Derecho".

\section{V.- CONCLUSIONES}

En atención a lo expuesto, podemos formular las siguientes conclusiones fundamentales:

El artículo 551.3 de la LOPJ habilita a la Ciudad Autónoma para designar a abogados colegiados externos que asuman la defensa y representación de la Ciudad ante los Juzgados y Tribunales.

Las externalización de letrados llevadas a cabo por parte de la Ciudad de su defensa jurídica y judicial constituye ciertamente un contrato administativo de servicios, por lo que a pesar de su estrecho vínculo con el contrato de arrendamiento de servicios no debe calificarse como civil por regla general, más aún si la propia LCSP los recoge expresamente como administrativos en su Anexo IV.

La gestión de las actuaciones judiciales de la Ciudad, debe caracterizarse por la preferencia en el encargo de los asuntos a los letrados propios de la Ciudad, decantándose por abogados externos sólo de forma subsidiaria, limitada y minoritaria, debiendo convertirse la externalización en la excepción y en ningún caso, la regla general.

Tanto si consideramos las contrataciones de abogados como administrativas como si se les reconoce el carácter de contratos privados de arrendamientos de servicios, deberá respetarse el cumplimiento de la LCSP en cuanto a su preparación y adjudicación, garantizándose los principios de libertad de acceso a las licitaciones, publicidad y transparencia de los procedimientos, y no discriminación e igualdad de trato entre los licitadores asegurando, en conexión con el objetivo de estabilidad presupuestaria y control del gasto, una eficiente utilización de los fondos destinados mediante la exigencia de la definición previa de las necesidades de defensa jurí- 
dica a satisfacer, la salvaguarda de la libre competencia y la selección de la oferta más ventajosa.

La utilización de la contratación menor de letrados presenta problemas respecto a la duración del contrato y la imposibilidad de fraccionamiento y prórroga del mismo por lo que esta vía debe tener carácter excepcional cumpliéndose estrictamente lo exigido por el art. 118 de la LCSP.

\section{BIBLIOGRAFÍA}

Gimeno Bevia (2017) La Defensa Privada de la Administración Pública. Gabilex n ${ }^{\circ}$ 9. Año 2017.

Rubio Beltrán (2018) La contratación de los servicios jurídicos en la ley 9/2017, de 8 de noviembre, de Contratos del Sector Público

García Alemany, A.J (2018) Régimen Jurídico de la Policía Local de Melilla. Revista Aldaba, no 43 